\title{
Brainstem ischaemia presenting as naloxone-reversible coma followed by downward
} gaze paralysis

\author{
SERGE GOLDMAN, ${ }^{*}$ MONIQUE JB CORDONNIER,† JACEK SZTENCEL \\ From the Departments of Neurology, ${ }^{*}$ Ophthalmology $\dagger$ and Radiology, $\ddagger$ Cliniques Universitaires de \\ Bruxelles, Hôpital Erasme, Université Libre de Bruxelles, Belgium
}

SUMMARY A 65-year-old man showed naloxone-reversible unconsciousness followed by downward gaze paralysis. CT scan suggested an ischaemic lesion in the mesodiencephalic region. This observation represents the first case of naloxone-reversible coma related to brainstem ischaemia.

Relief of unconsciousness by naloxone administration is considered a good therapeutic test for opiate intoxication. However, coma resulting from other causes such as encephalomyelitis ${ }^{1}$ and ethanol intoxication $^{2}$ also has been reported to be relieved by naloxone. More recently the same therapeutic response has been observed in two cases of ischaemic lesions of cerebral hemispheres. ${ }^{34}$ In this paper, we report a case of brainstem ischaemia presenting as naloxone-reversible unconsciousness followed by down-gaze paralysis, a rare neuroophthalmologic defect.

\section{Case report}

A 65-year-old Vietnamese was discovered in the early morning unconscious in bed. He had bilateral pin-point miosis, respiratory depression and no sign of obvious focal lesion. Narcotic overdose was suspected and naloxone 0.4 $\mathrm{mg}$ iv injection was followed within a few minutes by recovery of consciousness and adequate spontaneous ventilation. About 20 minutes later, the patient became unconscious again. A definitive recovery of consciousness was obtained through repeated $0.4 \mathrm{mg}$ naloxone iv injection together with $0.4 \mathrm{mg}$ im injection. Pupil size was then 2 $\mathrm{mm}$ each. The patient denied any drug intake and no opiate derivate could be detected in urine. Previous medical history was unremarkable except for a left otitis media with drum perforation.

Neurologic examination performed when the patient was conscious revealed him to be oriented in time and place with normal speech in Vietnamese and French. Men-

Address for reprint requests: Dr S Goldman, MD, Service of Neurology, Hôpital Erasme, Route de Lennik 808, B-1070 Brussels, Belgium.

Received 23 June 1983

Accepted 17 July 1983 tal functions were normal except for a retrograde amnesia going back to the evening before admission. The blood pressure was $180 / 100 \mathrm{~mm} \mathrm{Hg}$ and pulse was $70 /$ minute. Fundi were normal. Oculomotor examination revealed: (1) no skew deviation, (2) spontaneous slight upward deviation of both eyes (between 5 and 10 degrees) at rest, (3) no downgaze below direct forward gaze, (4) upgaze of normal amplitude with transitory nystagmus retractorius on extreme upward gaze, changing one week later to a slight vertical upbeat nystagmus, (5) eccentric upward fixation which was difficult to maintain, (6) horizontal gaze of normal amplitude with bilateral end-gaze nystagmus, (7) pupils $2 \mathrm{~mm}$ bilateral, equal but sluggish to light and near accommodation, (8) intact convergence. Otherwise, the physical examination was unremarkable. Recordings of ocular movement (electro-oculogram) revealed: (1) no downgaze below direct forward gaze during voluntary (in response to command) and visually guided saccades as well as during foveal pursuit stimulation by a smoothly downward moving target, (2) downward oculocephalic movement (tested by rapid passive hyperextension of the head) of normal amplitude, (3) gaze-evoked nystagmus present in extreme left-, right- and upgaze, (4) normal upward and lateral foveal pursuit, (5) optokinetic nystagmus present in all directions although of smaller amplitude in vertical plane particularly on upward stimulation, (7) normal left beating and normal right beating nystagmus on irrigation of right ear with cold and warm water respectively. Neither left nor bilateral simultaneous caloric stimulation were attempted because of previous left drum perforation.

Electroencephalogram was unremarkable as well as cerebrospinal fluid. Computed tomography (CT) performed seven days after admission showed two bilateral symmetric well-defined hypodense images at the posterior and caudal part of the third ventricle lateral walls (fig). There was no enhancement after contrast administration. Two other hypodensities were also observed bilaterally in the frontal white matter. A saccular dilation of the proximal part of the basilar artery was noted. Three months later, neurologic and neuro-ophthalmologic examination 


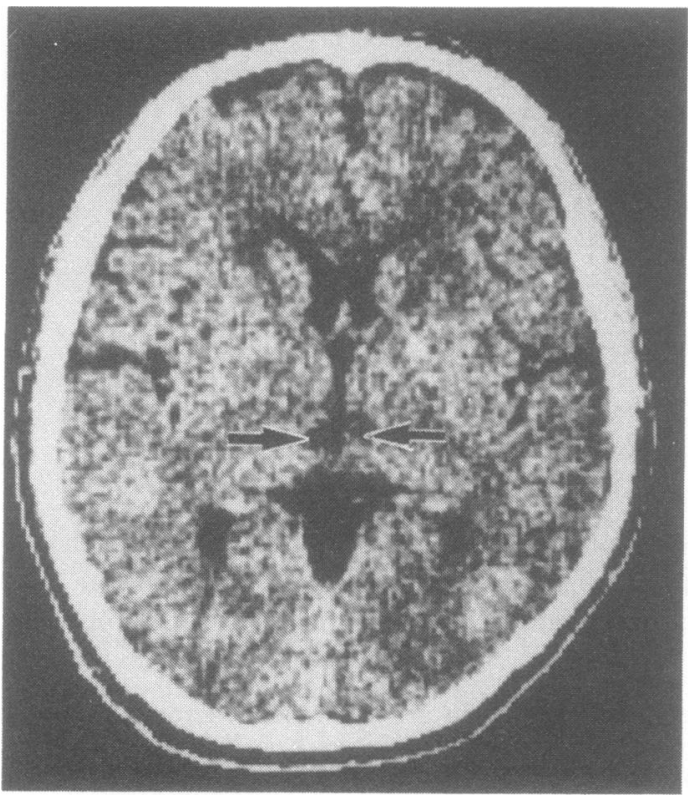

Fig CT scan performed on the 7th day: 2 bilateral symmetric well-defined hypodense images at posterior and caudal part of the lateral walls of the 3 rd ventricle (see arrows). Two other hypodensities are also present bilaterally in the frontal white matter.

was unchanged. At this time, CT scan showed a dilation of the third ventricle with shrinkage of the associated hypodense areas which had ill-defined margins. Nine months after the acute event, downgaze paralysis persists although small amplitude movement (10 degrees) below direct forward gaze is possible.

\section{Discussion}

Selective paralysis of downgaze has only been rarely described. Pierrot-Deseilligny et $a l^{5}$ published the eighth and ninth clinicopathological cases recently. In our observations oculographic recordings demonstrated abolition of downward gaze for foveal pursuit, voluntary and visually guided saccades and preservation of the oculocephalic reflex. CT localised the lesion bilaterally and medially at the mesodiencephalic level. These findings are consistent with the hypothesis that isolated abolition of downward gaze is related to lesion of the efferent tracts of the rostral interstitial nuclei of the medial longitudinal fasciculus. ${ }^{5}$ Miosis, respiratory depression, lack of focal neurologic deficit, and unconsciousness improved by intravenous injection of naloxone are the main features of opiate intoxication. In this paper, we describe another cause for such a clinical presentation: ischaemia of the brainstem. The ischaemic nature of the lesion is suggested in this case by the clinical history, by the CT scan images and their evolution and by the arterial lesion. Improvement of ischaemic deficit by naloxone has been demonstrated in clinical and experimental studies previously. ${ }^{3467}$ All the data concern hemispheric lesions in the territory of the internal carotid artery. In our case, the lesion is located in the territory of the vertebral basilar system. This is supported by the CT scan images and by the neuroophthalmologic deficit pointing to a lesion in the territory of the posterior thalamosubthalamic artery. ${ }^{5}$ As to the effect of naloxone, perhaps local opioid release was induced by the ischaemic lesion. There is a particular abundance of opioid in the region involved. ${ }^{8-11}$ Further studies are necessary to understand the effect of naloxone on coma with an ischaemic cause and to determine if this effect is related to the opioid content of the region involved.

\section{References}

' Brandt NJ, Terenius L, Jacobsen BB, et al. Hyperendorphin syndrome in a child with necrotizing encephalomyelopathy. N Engl J Med 1980;303:914 6.

${ }^{2}$ Lyon LJ, Antony J. Reversal of alcoholic coma by Naloxone. Ann Intern Med 1982;96:464-5.

${ }^{3}$ Baskin DS, Hosobuchi Y. Naloxone reversal of ischaemic neurological deficits in man. Lancet 1981;2:272-5 (patient 2).

${ }^{4}$ Iselin HU, Weiss P. Naloxone reversal of ichaemic neurological deficits. Lancet 1981;2:642-3. Letter.

5 Pierrot-Deseilligny CH, Chain F, Serdaru M, Escourolle R, Lhermitte F. Parinaud's syndrome-Electrooculographic and anatomical analyses of six vascular cases with deductions about vertical gaze organization in the premotor structures. Brain 1982;105:667-96.

- Hosobuchi Y, Baskin DS, Woo SK. Reversal of induced ischemic neurologic deficit in gerbils by the opiate antagonist naloxone. Science 1982;215:69-71.

${ }^{7}$ Faden AI, Hallenbeck JM, Brown CQ. Treatment of experimental stroke: Comparison of naloxone and thyrotropin releasing hormone. Neurology (Ny) 1982;32:1083-7.

${ }^{8}$ Watson SJ, Barchas JD, Li CH. $\beta$-lipotropin: localization of cells and axons in rat brain by immunocytochemistry. Proc Natl Acad Sci USA. 1977:74:5:5155-8.

9 Watson SJ, Akil H, Sullivan S, Barchas JD. Immunocytochemistry localization of methionine enkephalin: preliminary observations. Life Sci 1977;21:733-8.

${ }^{10}$ Sar M, Stumpf WE, Miller RJ, Chang K, Cuatrecasas P. Immunohistochemical localization of enkephalin in rat brain and spinal cord. J Comp Neurol 1978;182:17-38.

" Uhl GR, Goodman RR, Kuhar MJ, Childers SR, Snyders SH. Immunohistochemical mapping of enkephalin containing cell bodies, fibers and nerve terminals in the brain stem of the rat. Brain Res 1979;166:75-94. 